Research Article

\title{
Effect of the Supports' Positions on the Vibration Characteristics of a Flexible Rotor Shafting
}

\author{
Miaomiao Li $(\mathbb{D}$, Zhuo Li, Liangliang Ma, Rupeng Zhu $\mathbb{D}$, and Xizhi Ma
}

National Key Laboratory of Science and Technology on Helicopter Transmission, Nanjing University of Aeronautics and Astronautics, Nanjing, 210016, China

Correspondence should be addressed to Miaomiao Li; limiaomiao@nuaa.edu.cn

Received 11 November 2019; Accepted 26 December 2019; Published 12 February 2020

Academic Editor: Itzhak Green

Copyright $(2020$ Miaomiao Li et al. This is an open access article distributed under the Creative Commons Attribution License, which permits unrestricted use, distribution, and reproduction in any medium, provided the original work is properly cited.

In this study, we evaluated the effect of changing supports' position on the vibration characteristics of a three-support flexible rotor shafting. This dependency was first analyzed using a finite element simulation and then backed up with experimental investigations. By computing a simplified rotor shafting model, we found that the first-order bending vibration in a forward whirl mode is the most relevant deforming mode. Hence, the effect of the supports' positions on this vibration was intensively investigated using simulations and verified experimentally with a house-made shafting rotor system. The results demonstrated that the interaction between different supports can influence the overall vibration deformation and that the position of the support closer to the rotor has the greatest influence.

\section{Introduction}

The shafting is an indispensable part of transmission systems, such as helicopter tails, turbines, and ship propellers, and research constantly focusses on improving its design and performance. Most of these rotor shafting systems are designed to be flexible, because their working speed is generally higher than the critical speed [1]. When the rotor exceeds the critical speed, vibrations are generated due to mass imbalances, and severe vibrations can cause damage to the bearing and rotor structures and in turn affect the normal operation of the mechanical system [2,3]; a properly designed support can effectively reduce the vibrations of the rotor shafting at the critical speed and even avoid that the working speed reaches the resonance zone.

In shafting systems, it is commonly recognized that the position and features of the shaft's supports have a role in the system's overall stability. Xiao et al. [3], taking a magnetic levitation high-speed motor as their model, used a numerical method to study the influence of changing the bearing position on the vibration characteristics near the critical speed of a rotor-bearing system. They observed greater effects on the amplitude by changing the radial position, but less effects on the axial position. Liu et al. [4] investigated the influence of a radially displaced bearing on the vibration characteristics of a marine shafting system. The results demonstrated that changing the displacement of the bearing had an effect on the shafting vibration amplitude; however, the effect was not significant. Li et al. [5] studied the influence of bearing spacing on the acoustic vibration characteristics of underwater structures, finding that the bearings' spacing has little effect on underwater acoustic radiation; however, it can easily influence the vibration state of the propulsion shafting. $\mathrm{Xu}$ and $\mathrm{Li}[6]$ used the finite element method to analyze the influence of the bearings' position and aperture on the static stiffness and natural frequency of the rotor-bearing system of an electric spindle. They concluded that increasing both the span and aperture can improve the static stiffness of the spindle. Changing the bearing position at the rear end was found to significantly affect the frequency and mode of the spindle. With the same analysis method, Su et al. [7] and Qin et al. [8] observed that changing the bearings' stiffness and position can influence the natural frequency of vibration in ship shafting systems. $\mathrm{Ma}$ et al. [9] investigated the relationship between dynamic stiffness, damping coefficient, and rotor speed of different 
bearings. Kumar and Somnath [10] theoretically studied the effects of different bearing lengths, rotor speeds, and unbalanced forces reported in the literature on the dynamic characteristics of rotor-bearing systems. Generally, the effects of bearing stiffness on the critical velocity and vibration response characteristics of shafting systems have been widely investigated [11-14], as well as the methods to optimize the bearing stiffness, damping, length, gap, and diameter to improve the overall stability of a shafting [15-17]. Yücel and Saruhan [18] also used the Taguchi method to test the vibration of a rotor system under different coupling configurations, disk positions, and speeds in order to determine the combination of parameters that minimize deformation due to vibration. However, little is known on the effect of simultaneously changing different supports' positions, and how the overall supports' array can be configured to minimize overcritical vibrations.

It is common that support configurations, especially those of multibearing rotors, are designed so that they can guarantee optimal working strengths, without preliminarily paying attention to the magnitude of deforming vibrations, especially those that generate over the critical speed. However, attention needs to be paid to the final configuration of these rotors, to guarantee optimal performances at all conditions.

In this paper, a three-bearing rotor shafting system was chosen as the research object. The multifactor orthogonal test method was used to analyze how the interaction positions of the three supports affect the vibration characteristics at the critical speed and determine the optimal array. We then verified the computational results with experiments, testing a house-built flexible rotor shafting system.

\section{Flexible Rotor Shafting Model}

Our flexible rotor shafting system was composed of three bearing supports (I, II, and III), a turntable, a coupling, and two flexible shafts. Support I, a rigid support, was arranged on the left-end side of the shaft, between the end of the shaft and the turntable. Another rigid support, support III, was located at the right end of the shafting system, while the elastic support II was arranged at an intermediate position between supports I and III (an example is depicted in Figure 1(a)), the initial position of each support is zero (Figure 1(b)). The bearing of support II was equipped with a rubber ring containing a bushing, and the position of the bearing support was changed by moving the bushing. Several reference parameters are listed in Table 1. The UG software was used to computationally develop the solid model of each component, which could be assembled into the final rotor system by inputting its desired position and size parameters (Figure 1).

The ANSYS Workbench software was used to conduct our calculations; however, due to its limitations when applied to assembly simulations, we first extrapolated the supports' stiffness and damping parameters separately and then computed them in the model. Specifically, after obtaining the natural frequency and natural mode of vibration of the system, we extrapolated the radial vibration response parameters of the supports, which are listed in Table 2. For rigid supports I and III, the damping was set as zero, since their bearings, accurately lubricated with grease, were considered to be exempt from the effects of vibration. Afterwards, we pondered that, since the shape and structure of the model affect both the finite element meshing and the computational efficiency, the model needed to be appropriately simplified. The processed UG 3D model of the flexible rotor shafting system was imported into ANSYS, and the surface mapping grid and local size grid were used for mesh division and refinement. The bonded configuration was set for all contact zones. The bearing of body ground is added to the outer ring of the bushing to simulate the effect of the bearing on shafting. A remote displacement constraint was added to the outer-end surface of shaft I, to limit its axial rotation and movement. Figure 2 depicts the finished model of the rotor shafting system.

\section{Shafting Modal and Harmonic Response Analyses}

After optimization of our model, we first analyzed its modal response and harmonic response. Initially, we employed modal analysis to extrapolate the first six natural frequencies of the shafting system. The first four were selected for analysis and are reported in Table 3.

Figure 3 shows the modeled shapes of the shafting subject to the four natural vibrations in Table 3 . It can be seen that the first four modes are mainly bending vibrations, and that only a small difference in frequency is present between the first and second, and between the third and fourth modes. Since it has been demonstrated that a shaft mainly vibrates in a forward whirl mode [19], we decided to only consider the first-order bending vibration of the rotor shafting in our next analyses.

Since the natural frequency of a rotor shafting depends on the rotational speed, it is essential to evaluate its trend, as well as the critical speed. In the ANSYS software, during modal analysis, it is possible to compute different speeds and obtain a Campbell diagram. This plot is able to predict the speed of a rotating system at different frequencies and will report the critical speed relative to each natural frequency (Figure 4). The intersection of the isokinetic curve and each natural frequency curve is the critical speed point for that frequency. As can be seen in Figure 4, the first-order critical speed of our rotor shafting was $3221.8 \mathrm{r} / \mathrm{min}$ and the secondorder critical speed was $6597.4 \mathrm{r} / \mathrm{min}$.

In physical shafting systems, installation errors, manufacturing errors, and material unevenness are only some of the issues that distance their performance from ideality. Shafting systems are more or less eccentric, and eccentricity is one of the main factors that cause vibration [4]. Hence, we obtained the vibration deformation of the rotor shafting system at the critical speed by harmonic response analysis. Since this analysis takes into consideration the gyroscopic effect, it can only be solved by the full solution method. The meshing method and boundary conditions were the same as in the modal analysis, and the "rotating force" mode was used to simulate the eccentricity of the disk. 


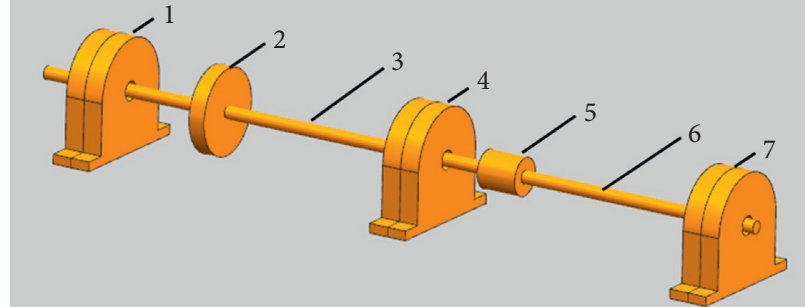

(a)

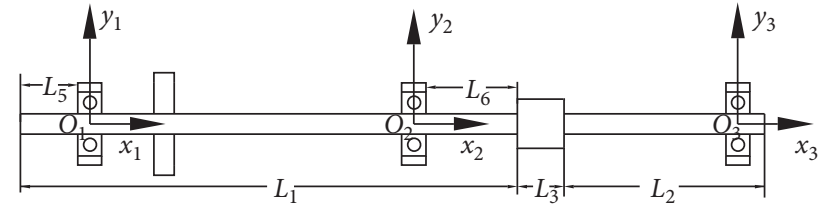

(b)

FIGURE 1: Schematic of the flexible rotor shafting system. 1-support I; 2-turntable; 3-shaft I; 4-support II; 5-coupling; 6-shaft II; 7-support III.

TABLE 1: Three-bearing rotor shafting reference parameters.

\begin{tabular}{lc}
\hline Parameter & $\begin{array}{c}\text { Numerical } \\
\text { value }\end{array}$ \\
\hline Shaft diameters $(D 1, \mathrm{~mm})$ & 14 \\
Shaft I length $(L 1, \mathrm{~mm})$ & 900 \\
Shaft II length $(L 2, \mathrm{~mm})$ & 362 \\
$\begin{array}{l}\text { Coupling length }(L 3, \mathrm{~mm}) \\
\text { Coupling outer diameter }(D 2, \mathrm{~mm})\end{array}$ & 34 \\
$\begin{array}{l}\text { Turntable thickness }(L 4, \mathrm{~mm}) \\
\text { Turntable outer diameter }(D 3, \mathrm{~mm})\end{array}$ \\
$\begin{array}{l}\text { Distance between support I and the left end of } \\
\text { bearing I }(L 5, \mathrm{~mm})\end{array}$ & 100 \\
$\begin{array}{l}\text { Distance between support II and the left end of } \\
\text { coupling II }(L 6, \mathrm{~mm})\end{array}$ & 151 \\
$\begin{array}{l}\text { Distance between support III and the right end of } \\
\text { shaft II }(L 7, \mathrm{~mm})\end{array}$ & 169 \\
\hline
\end{tabular}

TABLE 2: Supports' radial parameters.

\begin{tabular}{lcc}
\hline Support & Stiffness $k\left(\mathrm{~N} \cdot \mathrm{m}^{-1}\right)$ & Damping $c\left(\mathrm{~N} \cdot \mathrm{s} \cdot \mathrm{m}^{-1}\right)$ \\
\hline I & $2.89 \times 10^{8}$ & 0 \\
II & $3.8 \times 10^{6}$ & 75 \\
III & $2.89 \times 10^{8}$ & 0 \\
\hline
\end{tabular}

First, we derived the rotational force generated by the eccentric mass, and obtained a model; then, we inputted the first-order natural frequency to obtain the corresponding mode, as shown in Figure 5. The position of the maximum vibration deformation on the shafting varies with the change in the supporting position. In the experiment, it is impossible to predict the actual maximum vibration position, so it is a good choice to take the fixed position for vibration analysis. Therefore, for the convenience of the experiment, the independent variable was chosen to be the position between support I and support II. As an example, for a distance of $428 \mathrm{~mm}$, the deformation was calculated to be $0.9616 \mathrm{~mm}$.

\section{Orthogonal Simulation Test Design}

As mentioned, the goal of our study was to evaluate the effect of the interaction position of the three supports of our flexible rotor shaft system on the vibration characteristics near the critical speed. To account for the interaction between factors (in an experiment, not only are the various factors at work but also the factors sometimes combine to

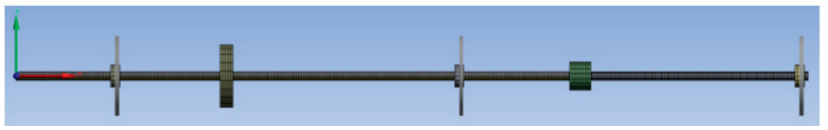

Figure 2: Optimized model of the flexible rotor shafting.

TABLe 3: First four natural frequencies and modes of the flexible rotor shafting system.

\begin{tabular}{lcc}
\hline$N$ & $f_{N}(\mathrm{~Hz})$ & Mode description \\
\hline 1 & 53.273 & FW; first-order bending vibration \\
2 & 53.665 & $\mathrm{BW}$; first-order bending vibration \\
3 & 111.28 & $\mathrm{FW}$; second-order bending vibration \\
4 & 111.5 & $\mathrm{BW}$; second-order bending vibration \\
\hline
\end{tabular}

influence a certain indicator, which is called interaction), we used the $L_{27}\left(3^{13}\right)$ orthogonal table, with the level design factors shown in Table 4 . The direction of the coordinate axis is marked in Figure 2. The $(+)$ direction of shifting the support's positions is consistent with the direction of the coordinate axis. To reduce the variability of the possible supports' positions, we restricted their values based on the movement limitations of the physical model prepared in our laboratory, making sure to reflect the exact adjustment ranges as much as possible. Tables 5 and 6 list the orthogonal test's scheme and report different calculated parameters that account for the varied bearing positions. By comparing different matches, we were able to find the optimal combination of supports' positions and, in turn, to find the minimal value of vibration deformation at the critical speed of our shafting system. Analyzing the direct correlation between single positions (I, II, or III) and the impact of the interaction on the vibration, we were able to determine which parameter has the greatest contribution.

\section{Analysis of Simulation Results}

Tables 5 and 6 show different parameters, useful to evaluate the influence of the supports' position on the amount of vibration deformation under the first-order bending vibration mode. In Figure 6, for a quicker evaluation, we plotted the vibration deformation and the maximum vibration deformation values for each of the set of parameters 


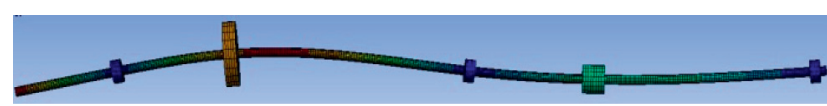

(a)

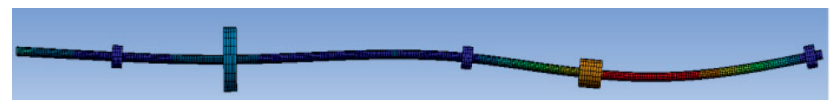

(c)

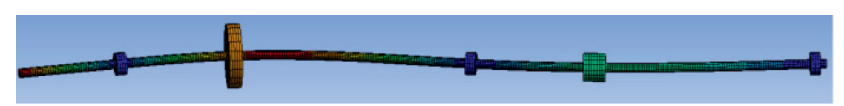

(b)

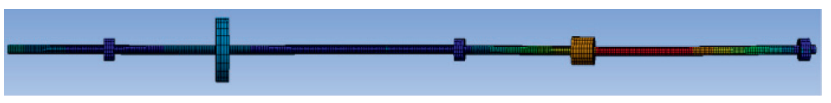

(d)

Figure 3: Projected effect of the first four modes of vibration on the flexible shafting. (a) First mode. (b) Second mode. (c) Third mode. (d) Fourth mode.

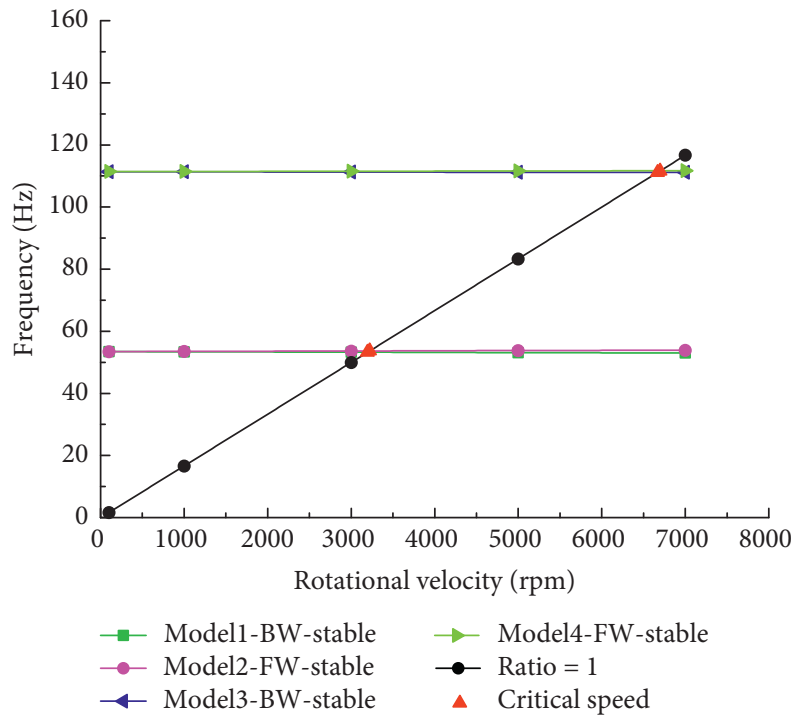

Figure 4: Campbell diagram of our flexible shafting system model.

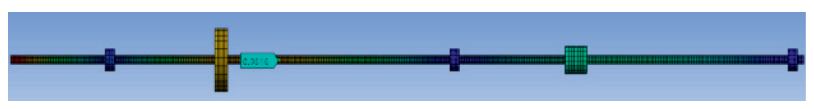

FiguRe 5: Harmonic response mode of our flexible shafting.

in Table 5. The two curves basically have the same trends; consequently, we could safely use the vibration deformation amount as the only target parameter. From the $R x$ values in Table 6, we found that the position of support I had the greatest influence on the vibration deformation, and the effect of the interaction support I $\times$ II was slightly larger than that of the position of support II. In short, the following influence trend was observed: support I $>$ interaction support I $\times$ II $>$ support II $>$ support III $\approx$ interaction support I $\times$ III $>$ interaction support II $\times$ III. Therefore, we obtained a set of conditions that allowed us to determine the optimal combination of supports' positions and modulate it as needed according to its effect on the overall vibration. Figure 7 shows the effect of changing the positions of the three supports on the vibration deformation. If support I is positioned at $0 \mathrm{~mm}$, the deformation is the highest; the farther the position of support III is from the shaft's end, the smaller the vibration deformation is. From our results, we found that the minimum deformation could be achieved when supports I, II, and III were placed at $40 \mathrm{~mm}, 0 \mathrm{~mm}$, and
TABLE 4: Orthogonal test level factors of the supports' positions.

\begin{tabular}{lccc}
\hline $\mathrm{m}$ & Level $\mathrm{i}$ & Level ii & Level iii \\
\hline$x_{\mathrm{I}}(\mathrm{mm})$ & -40 & 0 & 40 \\
$x_{\text {II }}(\mathrm{mm})$ & -40 & 0 & 40 \\
$x_{\text {III }}(\mathrm{mm})$ & -60 & -30 & 0 \\
\hline
\end{tabular}

${ }^{*} x_{\mathrm{I}}=$ support I position; $x_{\mathrm{II}}=$ support II position; $x_{\mathrm{III}}=$ support III position. All the positions refer to the distance from the reference positions listed in Table 1.

$-60 \mathrm{~mm}$, respectively. If we ignored the interaction between the factors, Figure 7 indicates that $40 \mathrm{~mm},-40 \mathrm{~mm}$, and $-60 \mathrm{~mm}$ were the optimal positions of supports I, II, and III, respectively. However, we know that the interaction of the three supports also play a role, which makes this set of conditions unsuitable for practical applications. Hence, to determine the actual optimal positions, we had to first determine the position of support $\mathrm{I}$, which is the parameter that influenced vibration the most; from there, the optimal position of support II could be determined, according to the interaction support I $\times$ II. Finally, we could set the optimal position of support III (it was not necessary to first determine the interaction support $\mathrm{I} \times \mathrm{III}$; its influence on vibration is similar to that of $x_{\text {III }}$ ). Hence, a total of six parameters (three absolute positions and three distances) can be determined by only obtaining three $\left(x_{\mathrm{I}}, x_{\mathrm{I} \times \mathrm{II}}\right.$, and $\left.x_{\text {III }}\right)$. To better evaluate the influence of $x_{\text {IXII }}$, Table 7 and Figure 8 summarize the results presented in Tables 5 and 6 . Figure 8 shows that setting the position of support II to $0 \mathrm{~mm}$, support I should be placed at $40 \mathrm{~mm}$ to achieve the lowest deformation; however, if the system shifts by $-40 \mathrm{~mm}$ (support I at $0 \mathrm{~mm}$ and support II at $-40 \mathrm{~mm}$ ), the vibration deformation would double. In summary, $40 \mathrm{~mm}, 0 \mathrm{~mm}$, and $-60 \mathrm{~mm}$ are excellent positions for supports I, II, and III, respectively.

\section{Experimental Device and Testing Scheme}

To apply the computational model in practice, we built a test platform consisting of a three-support rotor test bench, a signal acquisition device (uT3408FRS-DY, Youtai Electronics, China), a speed controller, a computer, and a displacement sensor (Figure 9).

The three-support rotor test bench consisted of a base, a drive motor, two flexible shafts, a counterweight disc, two couplings, and three supports. The parameters of the drive 
TABLE 5: Orthogonal test scheme and results of the support position parameters.

\begin{tabular}{|c|c|c|c|c|c|c|c|c|c|c|c|}
\hline$n$ & $\begin{array}{c}x_{\mathrm{I}} \\
(\mathrm{mm})\end{array}$ & $\begin{array}{c}x_{\mathrm{II}} \\
(\mathrm{mm})\end{array}$ & $\begin{array}{c}x_{\mathrm{I} \times \mathrm{II}} \\
(\mathrm{mm})\end{array}$ & $\begin{array}{c}x_{\mathrm{I} \times \mathrm{II}} \\
(\mathrm{mm})\end{array}$ & $\begin{array}{c}x_{\mathrm{III}} \\
(\mathrm{mm})\end{array}$ & $\begin{array}{c}x_{\mathrm{I} \times \mathrm{III}} \\
(\mathrm{mm})\end{array}$ & $\begin{array}{l}x_{\mathrm{I} \times \mathrm{III}} \\
(\mathrm{mm})\end{array}$ & $\begin{array}{l}x_{\mathrm{II} \times \mathrm{III}} \\
(\mathrm{mm})\end{array}$ & $\begin{array}{l}x_{\mathrm{II} \times \mathrm{III}} \\
(\mathrm{mm})\end{array}$ & $u x_{n}(\mathrm{~mm})$ & $\begin{array}{c}u x_{n \max } \\
(\mathrm{mm})\end{array}$ \\
\hline 1 & -40 & -40 & -40 & -40 & -60 & -40 & -60 & -40 & -60 & 0.0102 & 0.0109 \\
\hline 2 & -40 & -40 & -40 & -40 & -30 & 0 & -30 & 0 & -30 & 0.0065 & 0.0069 \\
\hline 3 & -40 & -40 & -40 & -40 & 0 & 40 & 0 & 40 & 0 & 0.0035 & 0.0052 \\
\hline 4 & -40 & 0 & 0 & 0 & -60 & -40 & -60 & 0 & -30 & 0.0082 & 0.0086 \\
\hline 5 & -40 & 0 & 0 & 0 & -30 & 0 & -30 & 40 & 0 & 0.0105 & 0.011 \\
\hline 6 & -40 & 0 & 0 & 0 & 0 & 40 & 0 & -40 & -60 & 0.0129 & 0.0135 \\
\hline 7 & -40 & 40 & 40 & 40 & -60 & -40 & -60 & 40 & 0 & 0.0279 & 0.0287 \\
\hline 8 & -40 & 40 & 40 & 40 & -30 & 0 & -30 & -40 & -60 & 0.0305 & 0.0313 \\
\hline 9 & -40 & 40 & 40 & 40 & 0 & 40 & 0 & 0 & -30 & 0.0332 & 0.0341 \\
\hline 10 & 0 & -40 & 0 & 40 & -60 & 0 & 0 & -40 & -30 & 0.0574 & 0.0773 \\
\hline 11 & 0 & -40 & 0 & 40 & -30 & 40 & -60 & 0 & 0 & 0.0749 & 0.1002 \\
\hline 12 & 0 & -40 & 0 & 40 & 0 & -40 & -30 & 40 & -60 & 0.1318 & 0.1744 \\
\hline 13 & 0 & 0 & 40 & -40 & -60 & 0 & 0 & 0 & 0 & 0.1717 & 0.2224 \\
\hline 14 & 0 & 0 & 40 & -40 & -30 & 40 & -60 & 40 & -60 & 0.353 & 0.4547 \\
\hline 15 & 0 & 0 & 40 & -40 & 0 & -40 & -30 & -40 & -30 & 0.9616 & 1.2336 \\
\hline 16 & 0 & 40 & -40 & 0 & -60 & 0 & -60 & 40 & -60 & 0.0902 & 0.1139 \\
\hline 17 & 0 & 40 & -40 & 0 & -30 & 40 & -60 & -40 & -30 & 0.0668 & 0.0842 \\
\hline 18 & 0 & 40 & -40 & 0 & 0 & -40 & -30 & 0 & 0 & 0.05 & 0.063 \\
\hline 19 & 40 & -40 & 40 & 0 & -60 & 40 & -30 & -40 & 0 & 0.0187 & 0.0444 \\
\hline 20 & 40 & -40 & 40 & 0 & -30 & -40 & 0 & 0 & -60 & 0.006 & 0.0059 \\
\hline 21 & 40 & -40 & 40 & 0 & 0 & 0 & -60 & 40 & -30 & 0.007 & 0.0147 \\
\hline 22 & 40 & 0 & -40 & 40 & -60 & 40 & -30 & 0 & -60 & 0.0033 & 0.0048 \\
\hline 23 & 40 & 0 & -40 & 40 & -30 & -40 & 0 & 40 & -30 & 0.0081 & 0.0154 \\
\hline 24 & 40 & 0 & -40 & 40 & 0 & 0 & -60 & -40 & 0 & 0.0113 & 0.0223 \\
\hline 25 & 40 & 40 & 0 & -40 & -60 & 40 & -30 & 40 & -30 & 0.0135 & 0.0261 \\
\hline 26 & 40 & 40 & 0 & -40 & -30 & -40 & 0 & -40 & 0 & 0.0138 & 0.0264 \\
\hline 27 & 40 & 40 & 0 & -40 & 0 & 0 & -60 & 0 & -60 & 0.014 & 0.0267 \\
\hline
\end{tabular}

${ }^{*} n=$ test number, $x_{\mathrm{I}}=$ support I position; $x_{\mathrm{II}}=$ support II position; $x_{\mathrm{III}}=$ support III position; $x_{\mathrm{I} \times \mathrm{II}}=$ interaction support I $\times$ II; $u x_{n}=$ amount of vibration deformation for the set of parameters reported in the $n^{\text {th }}$ row; $u x_{n \max }=$ the maximum vibration deformation for the set of parameters reported in the $n^{\text {th }}$ row. All the positions refer to the distance from the reference positions listed in Table 1.

TABLE 6: Elaboration of the supports' position parameters.

\begin{tabular}{|c|c|c|c|c|c|c|c|c|c|}
\hline & $x_{\mathrm{I}}(\mathrm{mm})$ & $x_{\mathrm{II}}(\mathrm{mm})$ & $x_{\mathrm{I} \times \mathrm{II}}(\mathrm{mm})$ & $x_{\mathrm{I} \times \mathrm{II}}(\mathrm{mm})$ & $x_{\text {III }}(\mathrm{mm})$ & $x_{\text {I } \times \text { III }}(\mathrm{mm})$ & $x_{\text {I } \times \text { III }}(\mathrm{mm})$ & $x_{\text {II } \times \text { III }}(\mathrm{mm})$ & $x_{\text {II } \times \text { III }}(\mathrm{mm})$ \\
\hline$S x_{\mathrm{i}}$ & 0.1434 & 0.316 & 0.2499 & 1.5478 & 0.4011 & 1.2122 & 0.5733 & 1.1832 & 0.6465 \\
\hline$S x_{\mathrm{ii}}$ & 1.9574 & 1.5406 & 0.337 & 0.2703 & 0.5701 & 0.3991 & 1.2264 & 0.3624 & 1.1623 \\
\hline$S x_{\mathrm{iii}}$ & 0.0957 & 0.3399 & 1.6096 & 0.3784 & 1.2253 & 0.579 & 0.3906 & 0.6447 & 0.3815 \\
\hline$K x_{\mathrm{i}}$ & 0.0159 & 0.0351 & 0.0278 & 0.1720 & 0.0446 & 0.1347 & 0.0637 & 0.1315 & 0.0718 \\
\hline$K x_{\mathrm{ii}}$ & 0.2175 & 0.1712 & 0.0374 & 0.0300 & 0.0633 & 0.0443 & 0.1363 & 0.0403 & 0.1291 \\
\hline$K x_{\mathrm{iii}}$ & 0.0106 & 0.0378 & 0.1788 & 0.0420 & 0.1361 & 0.0643 & 0.0434 & 0.0716 & 0.0424 \\
\hline$R x$ & 0.2069 & 0.1361 & 0.1510 & 0.1420 & 0.0915 & 0.0903 & 0.0929 & 0.0912 & 0.0868 \\
\hline
\end{tabular}

${ }^{*} \mathrm{i}$, ii, iii = test levels; $S x_{\mathrm{i}}, S x_{\mathrm{ii}}, S x_{\mathrm{iii}}=$ sums of the vibration deformation amounts at the corresponding level and for the relative position $x_{n}$; $K x_{\mathrm{i}}, K x_{\mathrm{ii}}$, $K x_{\mathrm{iii}}=$ average values of the test factor indexes at the corresponding level at the relative position $x_{n} ; R x=$ the range of each $x_{n}$.

motor are shown in Table 8. We made sure to configurate the test platform to allow for a convenient adjustment of the supports' positions: two parallel rows of convex grooves were opened on the base and a slider with a threaded hole was placed on the lower part of the convex groove. The bearing seat and the slider were fixed to the base with bolts. Supports I and III were rigid supports, while the movable support II was elastic. Before each test, the desired position of each support was marked on the base of the test bench; the lock nut and the bolts on the bearing seat were loosened, the supports were moved, and then fixed in the desired positions. Then, the lock nut and the bolts were tightened back.
The combination of the signal acquisition device and the eddy current displacement sensor allowed us to monitor the vibration amplitude and time dependency, the axial trajectory, and other information, in real time, and to input each collected signal into the signal acquisition device. After testing the samples under high-frequency generating stimuli, we were able to obtain the time-domain response data of the bending vibrations of the shafting and import them into the computer through the acquisition system. The data could be saved offline in the computer and later analyzed to comprehensively investigate the dynamic characteristics of the shafting. 


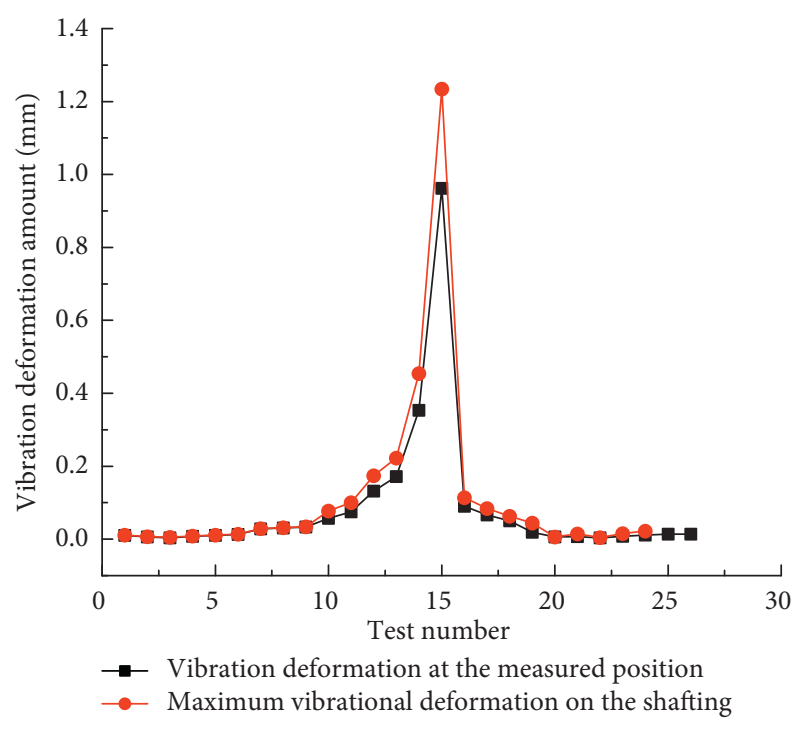

Figure 6: Comparison between the vibration deformation of the measured position at the next critical speed and the maximum vibration deformation on the shaft in the simulation.

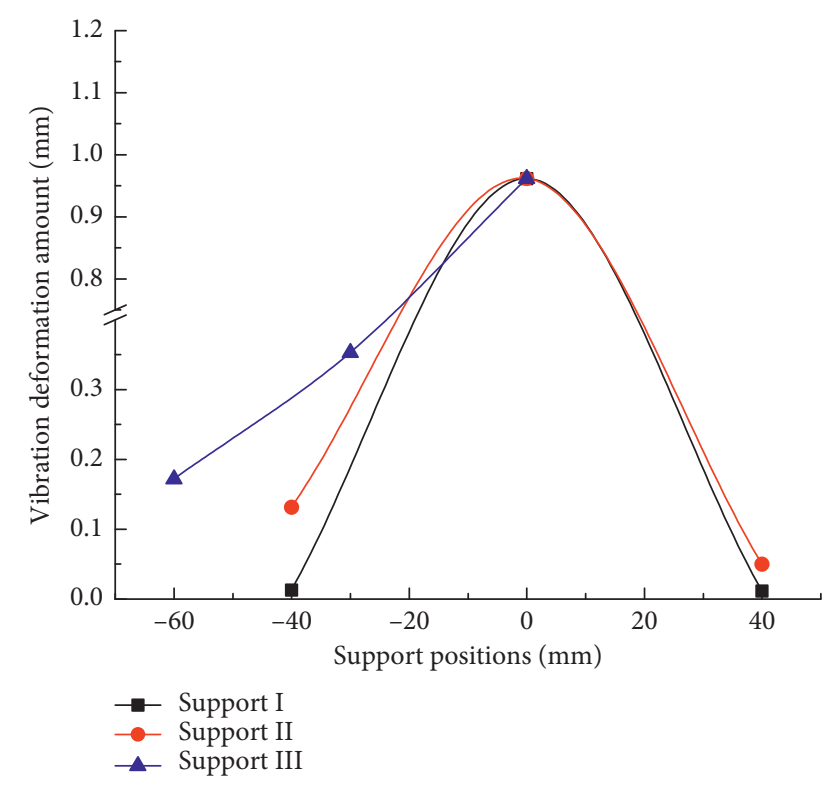

FIGURE 7: Relationship between supports' positions and vibration deformation.

TABle 7: Effects of interaction support $\mathrm{I} \times$ II.

\begin{tabular}{lcccc}
\hline$x_{\mathrm{I}}(\mathrm{mm})$ & $x_{\mathrm{II}}(\mathrm{mm})$ & $n$ & $S x_{\text {I×II }}(\mathrm{mm})$ & $K x_{\text {I } \times \text { II }}(\mathrm{mm})$ \\
\hline-40 & -40 & $1,2,3$ & 0.0202 & 0.0067 \\
-40 & 0 & $4,5,6$ & 0.0316 & 0.0105 \\
-40 & 40 & $7,8,9$ & 0.0916 & 0.0305 \\
0 & -40 & $10,11,12$ & 0.2641 & 0.0880 \\
0 & 0 & $13,14,15$ & 1.4863 & 0.4954 \\
0 & 40 & $16,17,18$ & 0.207 & 0.0690 \\
40 & -40 & $19,20,21$ & 0.0317 & 0.0106 \\
40 & 0 & $22,23,24$ & 0.0227 & 0.0076 \\
40 & 40 & $25,26,27$ & 0.0413 & 0.0138 \\
\hline
\end{tabular}

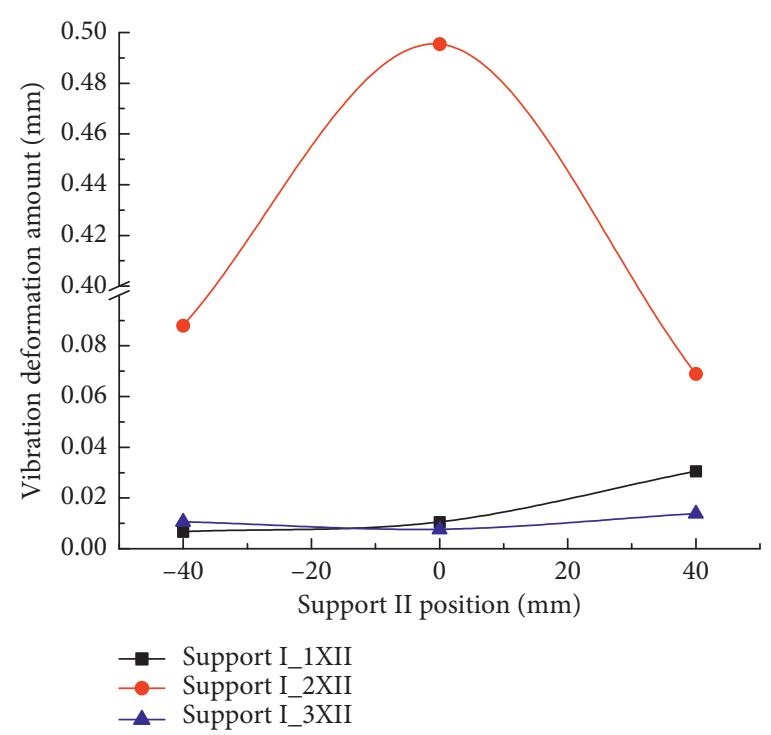

FIgURE 8: Relationship between $x_{\text {I×II }}$ and vibration deformation.

The speed controller could be either adjusted manually or programmed for automatic speed regulation. The latter allowed to select amongst a range of speed adjustment modes, achieved by inputting the target speed and acceleration time. For our experiments, we chose automatic speed regulation, with a steady speed of $4800 \mathrm{rpm}$ and a linear acceleration of $5 \mathrm{rps}$, starting from a stationary motor.

The eddy current displacement sensor was placed at an intermediate position between supports I and II. The sensor was used to measure the radial bending vibration deformation of the shafting in a range between 0 and $3 \mathrm{~mm}$. The output voltage was set to be zero when the probe was $2 \mathrm{~mm}$ from the shaft. Before the test, the sampling frequency was set to $512 \mathrm{~Hz}$. The specific parameters of the current displacement sensor are shown in Table 9.

To verify our computational results, we initially screened the effect of the positions reported in Figure 7 on the vibration displacement at the relative critical speeds. As mentioned, these positions were obtained without considering the interaction between two supports. The results are shown in Table 10.

As mentioned, the second and third most relevant parameters in defining the effect on vibration displacement are the interaction support I $\times I I$, and the position of support III, and especially, the interaction support I $\times$ II is even more relevant at trans-critical speeds than the absolute position of support II. Hence, we proceeded and evaluated the effect of $x_{\text {IXII }}$ and $x_{\text {III }}$ on vibration displacement. By fixing the position of support I, we varied the position of supports II and III; the results are shown in Table 11.

\section{Analysis of Test Results}

The results reported in Table 10 are summarized in Figure 10. By comparing Figure 7 (simulation) with Figure 10 (test), we gladly noticed that the trends of the influence of 
(a)

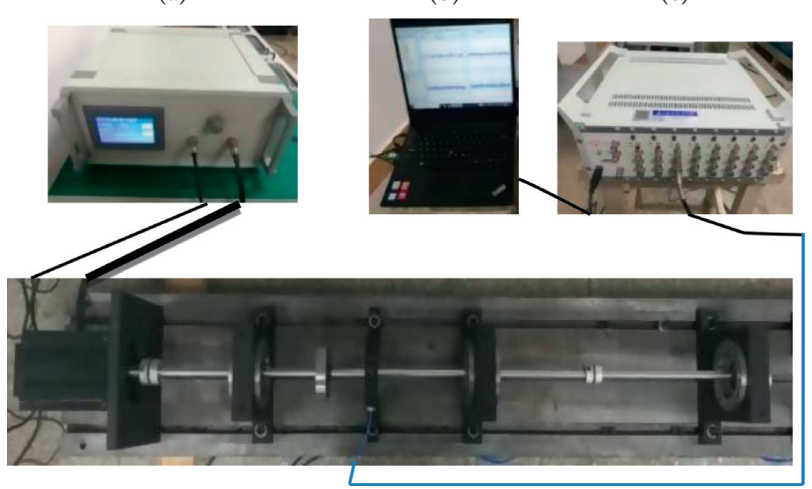

(d)
FIgURE 9: Three-support rotor test platform: (a) speed control device; (b) computer; (c) signal acquisition device; (d) multispan rotor test bench.

TABLE 8: Motor parameters.

\begin{tabular}{lc}
\hline Name & Numerical value \\
\hline Model & BLDC-130IN-315V \\
Voltage & DC, $315 \mathrm{~V}$ \\
Rated current & $10 \mathrm{~A}$ \\
Rated speed & $8000 \mathrm{rpm}$ \\
Rated power & $2000 \mathrm{~W}$ \\
\hline
\end{tabular}

TABLE 9: Eddy current displacement sensor parameters.

\begin{tabular}{lc}
\hline Name & Numerical value \\
\hline Probe model & ZA-210803-00-05-50-02 \\
Front model & ZA-210800-50-04-01-01 \\
Supply voltage & $\pm 15 \mathrm{~V}$ \\
Linear range & $0.50-3.50 \mathrm{~mm}$ \\
Standard sensitivity & $3.33 \mathrm{~V} \mathrm{~mm}^{-1}$ \\
Sensitivity error & $0.5 \%$ \\
\hline
\end{tabular}

TABLE 10: Effect of different absolute support positions on the overall vibration displacement (the interaction between support positions were not considered).

\begin{tabular}{lcccc}
\hline Test number & $x_{\mathrm{I}}(\mathrm{mm})$ & $x_{\mathrm{II}}(\mathrm{mm})$ & $x_{\mathrm{III}}(\mathrm{mm})$ & $u x(\mathrm{~mm})$ \\
\hline 1 & -40 & 0 & 0 & 0.383 \\
2 & 0 & 0 & 0 & 1.26 \\
3 & 40 & 0 & 0 & 0.299 \\
4 & 0 & -40 & 0 & 0.772 \\
5 & 0 & 40 & 0 & 0.848 \\
6 & 0 & 0 & -60 & 0.975 \\
7 & 0 & 0 & -30 & 1.06 \\
\hline
\end{tabular}

each set of positions on the vibration deformation were basically the same. However, the test bench certainly suffers from axial misalignment, bearing load effects, bolt preload, and manufacturing errors, which are difficult to be estimated and eliminated. Therefore, the numerical values of the test and the simulation were not compared.
TABLE 11: Influence of the interaction support $\mathrm{I} \times \mathrm{II}$ on vibration displacement.

\begin{tabular}{lcccc}
\hline Test number & $x_{\mathrm{I}}(\mathrm{mm})$ & $x_{\mathrm{II}}(\mathrm{mm})$ & $x_{\mathrm{III}}(\mathrm{mm})$ & $u x(\mathrm{~mm})$ \\
\hline 8 & -40 & 0 & -60 & 0.448 \\
9 & -40 & 40 & -60 & 0.72 \\
10 & -40 & 0 & -30 & 0.529 \\
11 & -40 & 40 & -30 & 0.781 \\
12 & -40 & 0 & 0 & 0.383 \\
13 & -40 & 40 & 0 & 0.791 \\
\hline
\end{tabular}

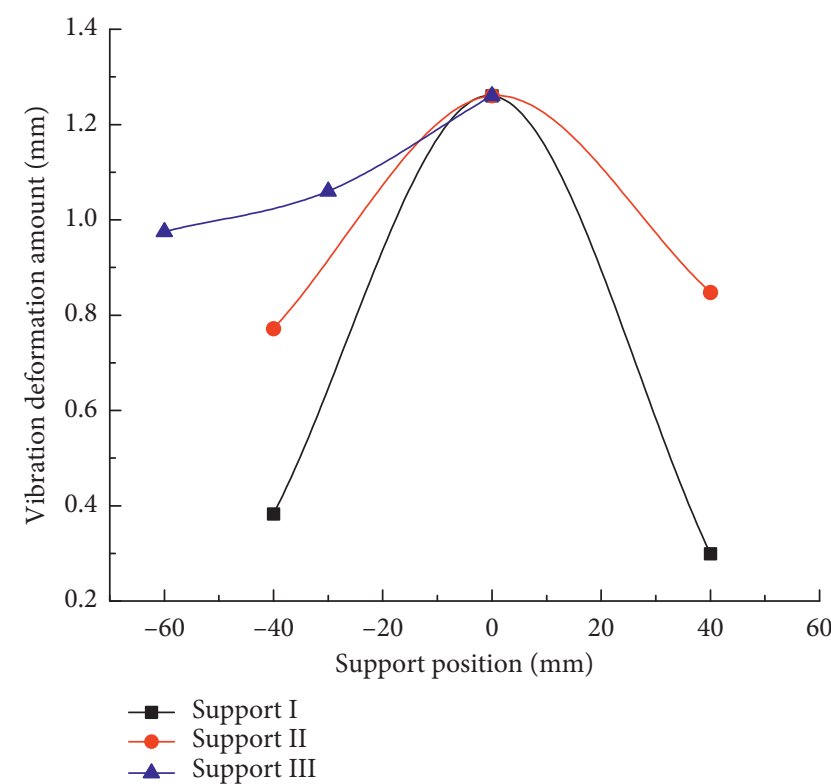

Figure 10: Influence of the supports' positions on vibration deformation, measured experimentally.

Figure 11 shows the case where the positions of support II and support III were kept constant and the position of the support I was changed. The deformation was measured at a precise position (between supports II and I); hence, the obtained deformation value refers to that position, and was measured when the critical speed was reached. Figure 11(a) shows the vibration waveform obtained when the three supports I, II, and III were positioned at $-40 \mathrm{~mm}, 0 \mathrm{~mm}$, and $0 \mathrm{~mm}$, respectively. In this configuration, the maximum vibration deformation across the first-order critical speed was $0.38 \mathrm{~mm}$. Figure 11(b) shows the vibration waveform when the all the three supports were placed at their reference position, with a corresponding vibration deformation of $1.26 \mathrm{~mm}$. Figure 11(c) shows the vibration waveform of the three supports at the $40 \mathrm{~mm}, 0 \mathrm{~mm}$, and $0 \mathrm{~mm}$ positions, where the maximum vibration deformation decreased to $0.299 \mathrm{~mm}$.

Figure 12 shows the case where only the position of support II was changed, and the shafting was subject to vibration deformation at the critical speed. For positions of $0 \mathrm{~mm},-40 \mathrm{~mm}$, and $0 \mathrm{~mm}$, the maximum vibration deformation across the first-order critical speed was $0.772 \mathrm{~mm}$ (Figure 12(a)), while at $0 \mathrm{~mm}, 40 \mathrm{~mm}$, and $0 \mathrm{~mm}$, the deformation increased to $0.848 \mathrm{~mm}$ (Figure 12(b)). 


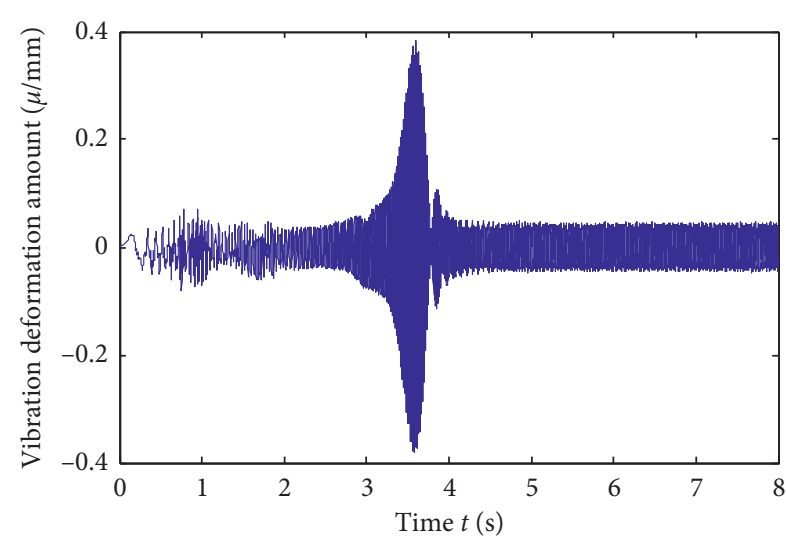

(a)

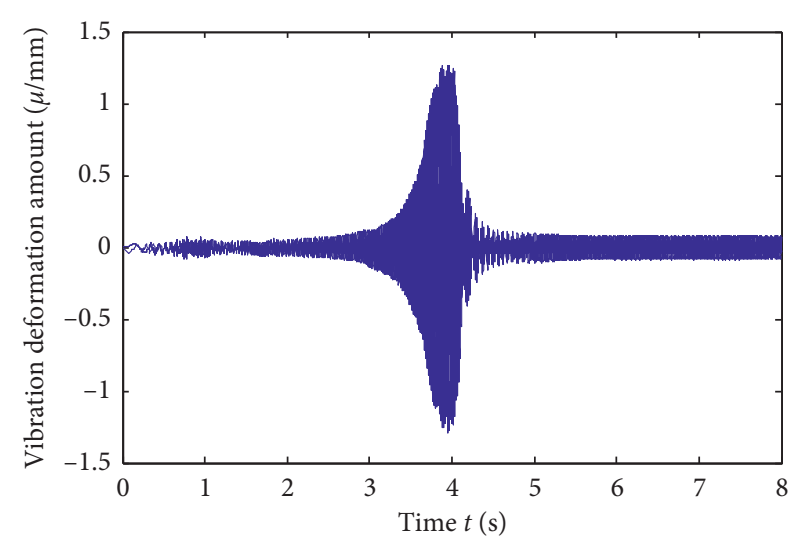

(b)

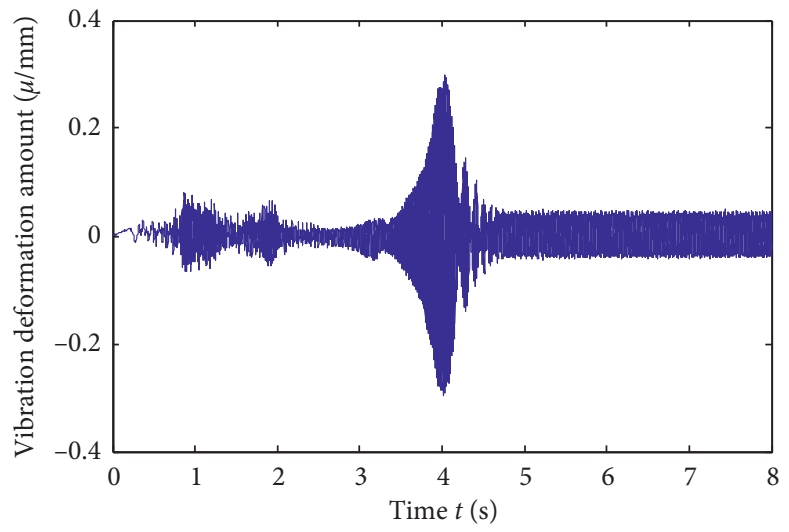

(c)

FIGURE 11: Effect of the position of support I on the vibration deformation of the shafting across the first-order critical speed. (a) Supports' positions $-40 \mathrm{~mm}, 0 \mathrm{~mm}, 0 \mathrm{~mm}$. (b) Supports' positions $0 \mathrm{~mm}, 0 \mathrm{~mm}, 0 \mathrm{~mm}$. (c) Supports' positions $40 \mathrm{~mm}, 0 \mathrm{~mm}, 0 \mathrm{~mm}$.

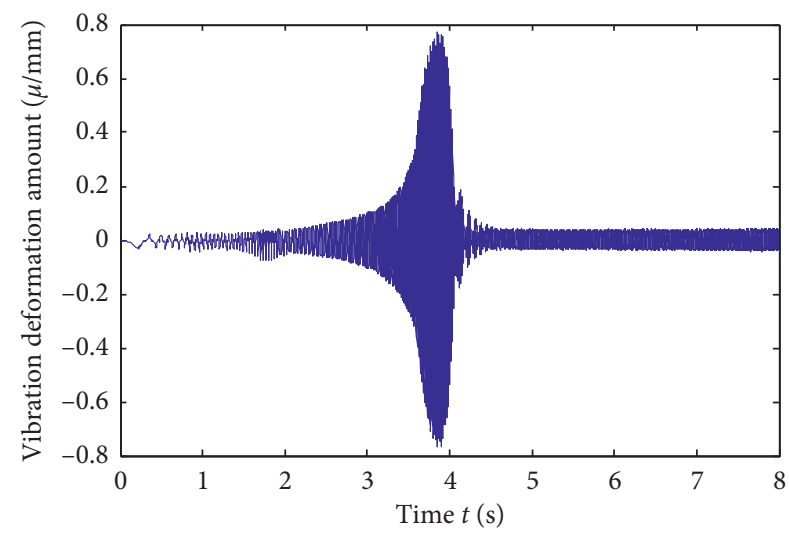

(a)

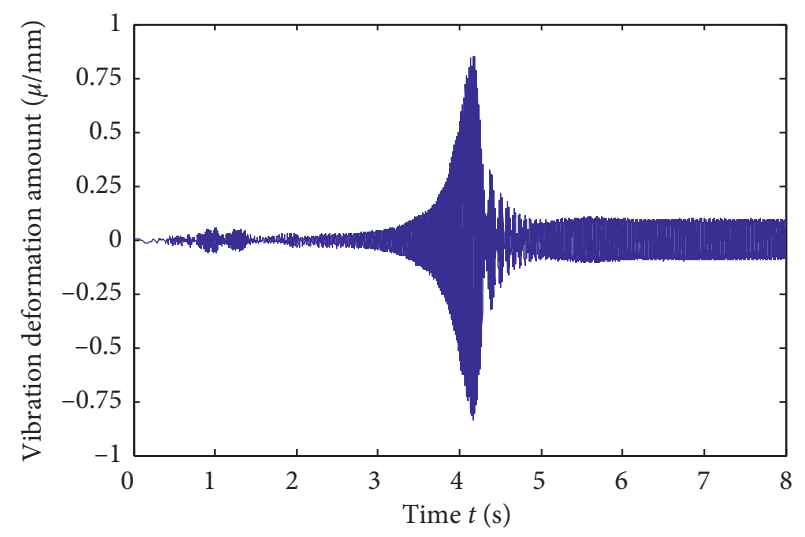

(b)

FIGURE 12: Effect of the position of support II on the vibration deformation of the shafting across the first-order critical speed. (a) Supports' positions $0 \mathrm{~mm},-40 \mathrm{~mm}, 0 \mathrm{~mm}$. (b) Supports' positions $0 \mathrm{~mm}, 40 \mathrm{~mm}, 0 \mathrm{~mm}$.

Figure 13 shows the waveform of the vibration in the case where only the position of support III was changed. Figure 13(a) shows the vibration waveform of the three supports at the $0 \mathrm{~mm}, 0 \mathrm{~mm}$, and $-60 \mathrm{~mm}$ positions, with the maximum of $0.975 \mathrm{~mm}$. If support III was moved to
$-30 \mathrm{~mm}$, the deformation reached $1.06 \mathrm{~mm}$ (Figure 13(b)). As can be seen from the test results, changing the position of support I to its optimal value reduced the vibration deformation by $76.27 \%$; in comparison, for supports II and III, the improvements were only $38.73 \%$ and $22.62 \%$, 


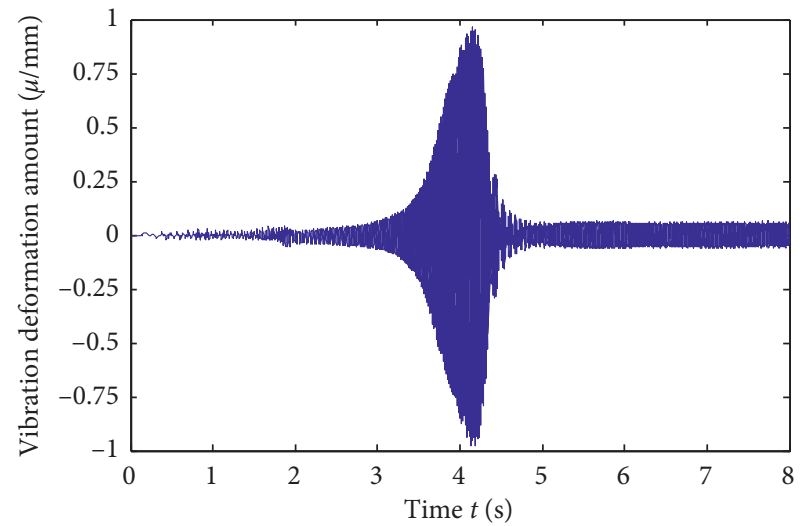

(a)

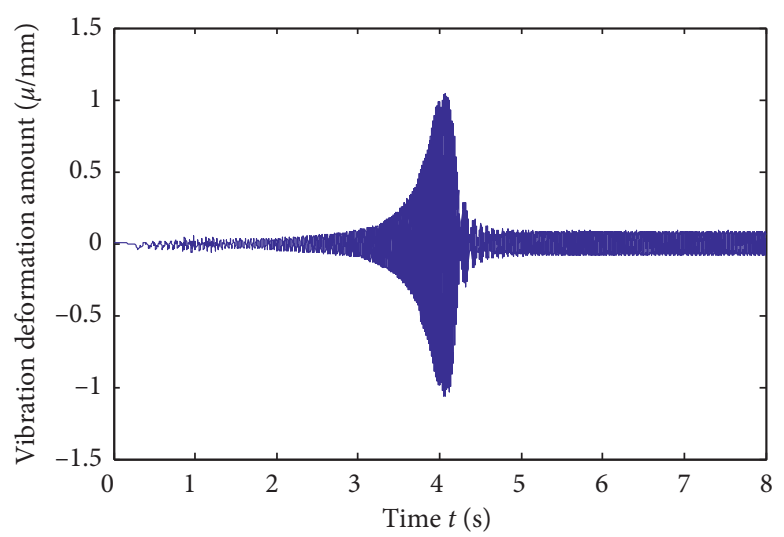

(b)

FIGURE 13: Effect of the position of support III on the vibration deformation of the shafting across the first-order critical speed. (a) Supports' positions $0 \mathrm{~mm}, 0 \mathrm{~mm},-60 \mathrm{~mm}$. (b) Supports' positions $0 \mathrm{~mm}, 0 \mathrm{~mm},-30 \mathrm{~mm}$.

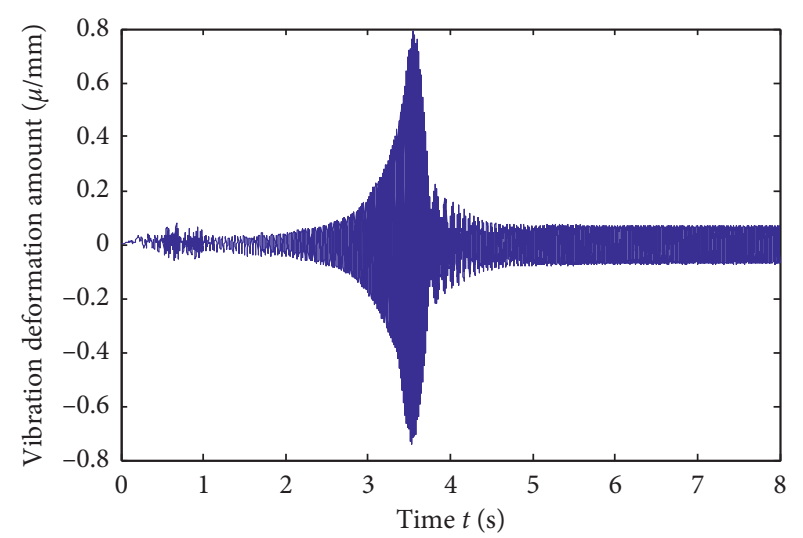

(a)

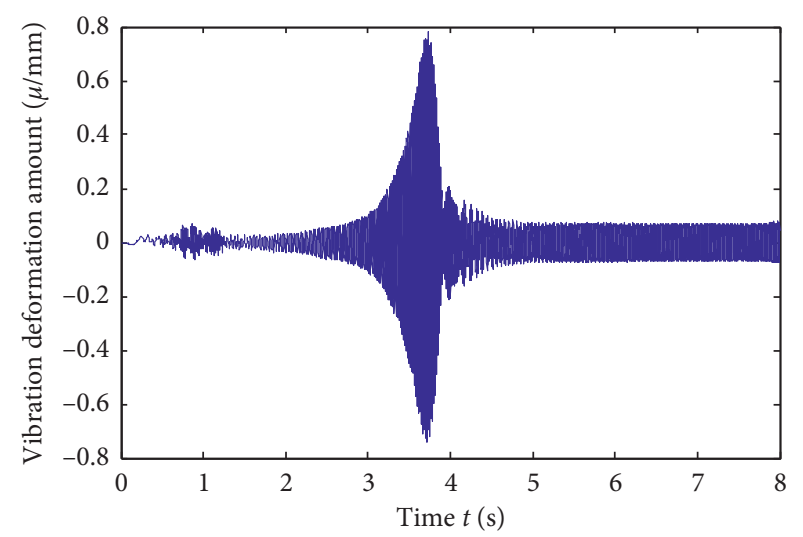

(c)

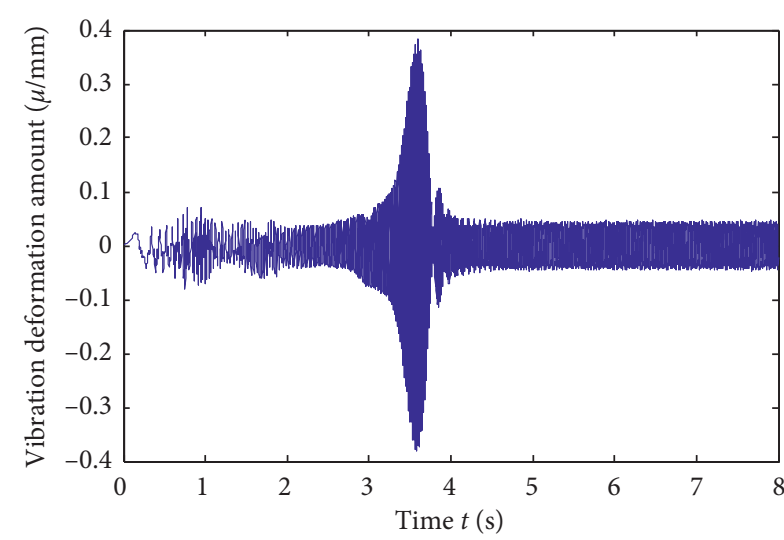

(b)

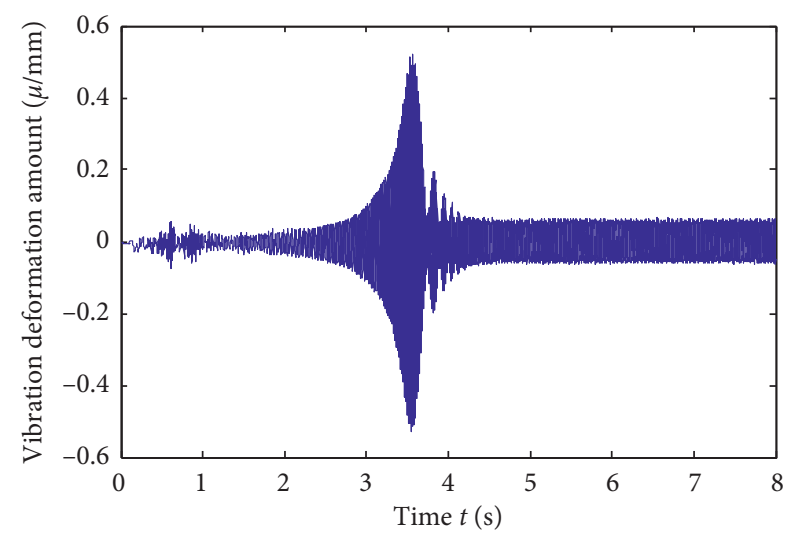

(d)

FIgURe 14: Continued. 


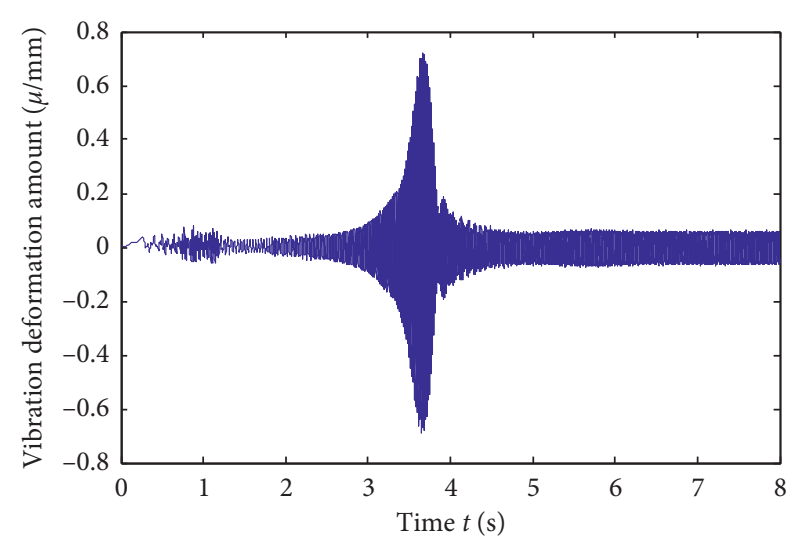

(e)

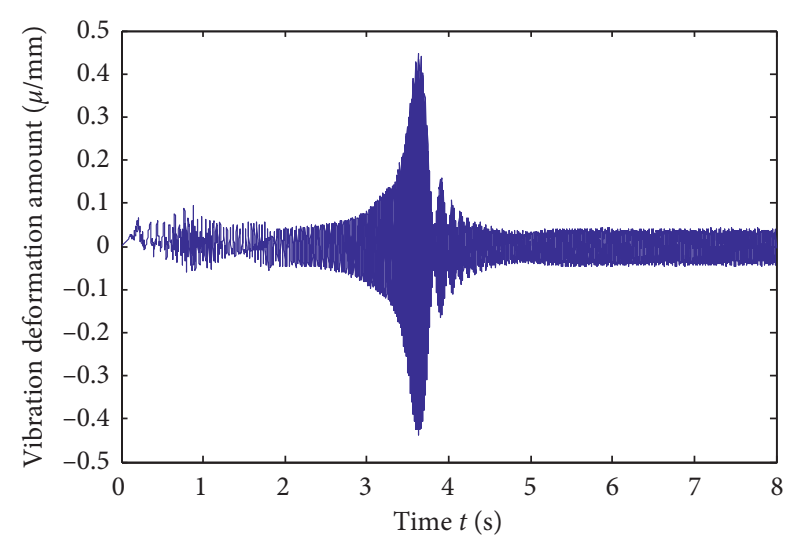

(f)

FIGURE 14: Effect of the interaction support I $\times$ II on the dynamic response of the shafting across the first-order critical speed. (a) Support position $-40 \mathrm{~mm}, 40 \mathrm{~mm}, 0 \mathrm{~mm}$. (b) Supports' positions $-40 \mathrm{~mm}, 0 \mathrm{~mm}, 0 \mathrm{~mm}$. (c) Supports' positions $-40 \mathrm{~mm}, 40 \mathrm{~mm},-30 \mathrm{~mm}$. (d) Supports' positions $-40 \mathrm{~mm}, 0 \mathrm{~mm},-30 \mathrm{~mm}$. (e) Support's positions $-40 \mathrm{~mm}, 40 \mathrm{~mm},-60 \mathrm{~mm}$. (f) Supports' positions $-40 \mathrm{~mm}, 0 \mathrm{~mm}$, $-60 \mathrm{~mm}$.

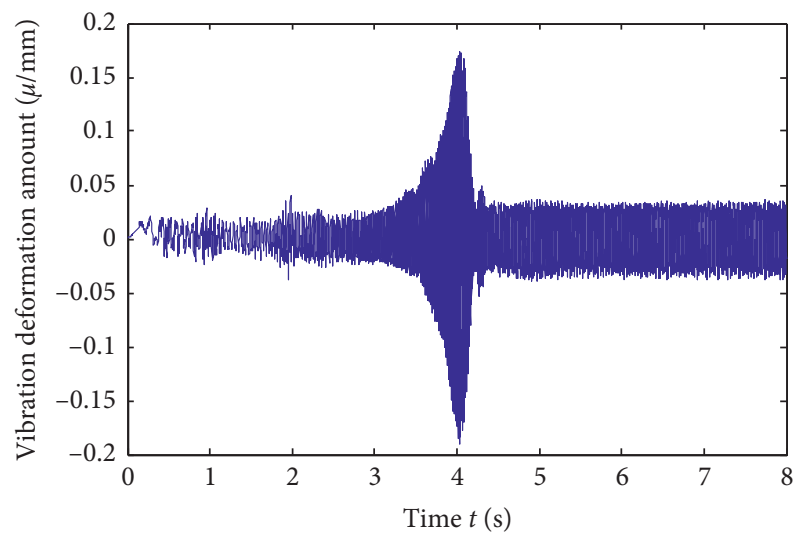

FIGURE 15: Support's positions $40 \mathrm{~mm}, 0 \mathrm{~mm},-60 \mathrm{~mm}$.

respectively. As a result, our experiments showed that the position of support I has the greatest influence on the vibration of the shafting over the first order of critical speed, while the position of the support III has the smallest influence. This is consistent with the simulation results.

Both numerical and experimental results show that when support II is at the $0 \mathrm{~mm}$ position, the vibration deformation at the first critical speed is the smallest. Due to the interdependence of different supports' positions, the interaction support I $\times$ II had a greater effect on the vibration deformation than the absolute position of support II. As can be seen from the comparison between (a) and (b), or between (c) and (d), or between (e) and (f) in Figure 14, the amount of vibration deformation when support II is at $0 \mathrm{~mm}$ is lower than that at $40 \mathrm{~mm}$ (with the same support I and III positions). That is, the interaction support I $\times$ II (support II at $40 \mathrm{~mm}$ ) has a larger deformation effect than support II (support II at the $0 \mathrm{~mm}$ ). These results are consistent with the conclusions of the simulation.

Amongst all the examined cases, we can conclude that the minimum vibration deformation across the first-order critical speed could be achieved with the $40 \mathrm{~mm}, 0 \mathrm{~mm}$, and $-60 \mathrm{~mm}$ combination (Figure 15), with a value of only $0.174 \mathrm{~mm}$. When the positions of the three supports were left unchanged (as the reference) a maximum vibration deformation of $1.26 \mathrm{~mm}$ was observed. The difference between these two aforementioned cases is an astonishing $86.19 \%$.

\section{Conclusion}

In this paper, the finite element simulation method was used to investigate the effect of the supports' positions of a three-support rotor shafting on the vibration characteristics near the critical speed. The numerical data were backed up by experimental observations, and the following conclusions were drawn. (a) The positions of the three supports have a great influence on the amount of vibration deformation near the first-order critical speed of the rotor shafting. In particular, the position of support I has the greatest influence. (b) Within a certain range, the vibration deformation first increased, and then decreased, when the positions of support I and support II were shifted to the right (Figure 10). For the same movement, the vibration deformation gradually and steadily increased for support III. (c) The effect of the position of support II on the vibration characteristics of the shafting was influenced by the position of support I position, which played a leading role.

\section{Data Availability}

The data used to support the findings of this study are included within the article.

\section{Conflicts of Interest}

The authors declare that they have no conflicts of interest. 


\section{Acknowledgments}

This research work was supported by the Fundamental Research Funds for Central Universities (nos. NT2018015) and the National Natural Science Foundation of China (nos. 51505215).

\section{Supplementary Materials}

The Excel sheet named Table10_1 represents the test data under test number 1 in the manuscript table 10 (Figure 11(a)). Similarly, the Excel sheet named Table10_2 represents the test data under test number 2 in the manuscript table 10 (Figure 11(b)), and the Excel sheet named Table10_3 represents the test under test number 3 in the manuscript table 10 (Figure 11(c)), the Excel sheet named Table10_4 represents the test data under test number 4 in the manuscript table 10 (Figure 12(a)), and the Excel sheet named Table10_5 represents the test data under test number 5 in the manuscript table 10 (Figure 12(b)), the Excel sheet named Table10_6 represents the test data under test number 6 in the manuscript table 10 (Figure 13(a)), and the Excel sheet named Table10_7 represents the test data under test number 7 in the manuscript table 10 (Figure 13(b)), the Excel sheet named Table11_8 represents the test data under test number 8 in the manuscript table 11 (Figure 14(f)), the Excel sheet named Table11_9 represents the test data under test number 9 in the manuscript table 11 (Figure 14(e)), and the Excel sheet named Table11_10 represents the test data under test number 10 in the manuscript table 11 (Figure 14(d)), the Excel sheet named Table11_11 represents the test data under test number 11 in the manuscript table 11 (Figure 14(c)), the Excel sheet named Table11_12 represents the test data under test number 12 in the manuscript table 11 (Figure 14(b)). The Excel sheet named Table11_13 represents the test data under test number 13 in the manuscript table 11 (Figure 14(a)). The Excel sheet named figure 15 represents the test data when the critical speed vibration amount is the smallest (Figure 15). (Supplementary Materials)

\section{References}

[1] A. A. El-Badawy, "Behavioral investigation of a nonlinear nonideal vibrating system," Journal of Vibration and Control, vol. 13, no. 2, pp. 203-217, 2007.

[2] B Peng, Research on Multi-Span Shaft Dynamics and Vibration Reduction via Smart Spring Support, Nanjing University of Aeronautics and Astronautics, Nanjing, China, 2017.

[3] L. Xiao, L. V. Nan, H. Ding et al., "Study on coupling vibration characteristics of rotor-bearing system for high speed magnetic suspension motor," Bearing, no. 7, pp. 1-4, 2016, in Chinese.

[4] J. Liu, Y. Cai, and G. Lai, "Calculation and experiment on influence of bearing displacement on vibration characteristic of marine shafting system," Journal of Dalian Maritime University, vol. 42, no. 4, pp. 61-66, 2016.

[5] H. Li, S. Zhu, and X. Weng, "Research on effects of shaft bearing stiffness and spacing on vibra-acoustic radiation of underwater structure," Marine Engineering, vol. 38, no. 9, pp. 57-61, 2016.
[6] J. Xu and W. Li, "Dynamic and static performance analysis of rotor-bearing system of electric spindle based on ANSYS," Mechanical Design and Manufacturing, vol. 17, no. 9, pp. 9-11, 2015, in Chinese.

[7] Z. Su, Li Zi, and Y. Xu, "Vibration characteristics and response analysis of shafting system of a certain type of working ship," Marine Engineering, vol. 45, no. 4, pp. 137-140, 2016, in Chinese.

[8] H. Qin, H. Zheng, and Z. Zhang, "Lateral vibration of a propulsion shafting system installed with a magnetic bearing," Shock and Vibration, vol. 37, no. 10, pp. 129-134, 2018, in Chinese.

[9] J. Ma, J. Dai, B. Sun et al., "Bearing support characteristics and its effect on axial dynamic characteristics," Noise and Vibration Control, vol. 31, no. 5, pp. 22-26, 2011, in Chinese.

[10] C. Kumar and S. Somnath, "Dynamic response of an unbalanced rigid rotor bearing system with a nonlinear hydrodynamic force," Journal of Computational and Nonlinear Dynamics, vol. 13, no. 9, Article ID 090909, 2018.

[11] V. T. Ngo and D. M. Xie, "Analysis behavior of a rig shafting vibration set changes bearing parameters," Applied Mechanics and Materials, vol. 437, pp. 98-101, 2013.

[12] J. Luo, Z. Liu, S. Yang et al., "The research on supporting stiffness of LP rotor of ultra-supercritical turbine," in Proceedings of the International Conference on Electrical and Control Engineering (ICECE), pp. 16-18, Yichang, China, September 2011.

[13] Z. Jaroslav and F. Petr, "A computational investigation on the reducing lateral vibration of rotors with rolling-element bearings passing through critical speeds by means of tuning the stiffness of the system supports," Mechanism and Machine Theory, vol. 46, no. 5, pp. 707-724, 2011.

[14] D. Han, H. Long, and J. Yang, "Dynamic characteristics of air cycle machine rotor system," Shock and Vibration, vol. 2018, Article ID 1257274, 16 pages, 2018.

[15] J. Khairul, "Vibration reduction of spindle-bearing system by design optimization," WSEAS Transactions on Applied and Theoretical Mechanics, vol. 13, pp. 85-91, 2018.

[16] B. S. Yang, S. P. Choi, and Y. C. Kim, "Vibration reduction optimum design of a steam-turbine rotor-bearing system using a hybrid genetic algorithm," Structural and Multidisciplinary Optimization, vol. 30, no. 1, pp. 43-53, 2005.

[17] R. B. Bhat, J. S. Rao, and T. S. Sankar, "Optimum journal bearing parameters for minimum rotor unbalance response in synchronous whirl," Journal of Mechanical Design, vol. 104, no. 2, pp. 339-344, 1982.

[18] E. Yücel and H. Saruhan, "Design optimization of rotorbearing system considering critical speed using Taguchi method," Proceedings of the Institution of Mechanical Engineers, Part E: Journal of Process Mechanical Engineering, vol. 231, no. 2, pp. 138-146, 2017.

[19] J. Gu, K. Ding, Q. Liu et al., Rotor Dynamics, pp. 25-137, Defense Industry Press, Beijing, China, 1985, in Chinese. 